\title{
Epistemic Immodesty and Embodied Rationality
}

\author{
Giovanni Rolla \\ Universidade Federal do Rio Grande do Sul \\ Departamento de Filosofia \\ Porto Alegre \\ Brasil \\ rollagiovanni@gmail.com
}

Article info

CDD: 120

Received: 09.04.2016; Revised: 21.06.2016; Accepted: 23.06.2016

DOI: http://dx.doi.org/10.1590/0100-6045.2016.V39N3.GR

Keywords:

Disjunctivism

Dream Skepticism

Rationality

Actionism

\begin{abstract}
Based on Pritchard's distinction $(2012,2016)$ between favoring and discriminating epistemic grounds, and on how those grounds bear on the elimination of skeptical possibilities, I present the dream argument as a moderate skeptical possibility that can be reasonably motivated. In order to block the dream argument skeptical conclusion, I present a version of phenomenological disjunctivism based on Noë's actionist account of perceptual consciousness (2012). This suggests that perceptual knowledge is rationally grounded because it is a form of embodied achievement - what I call embodied rationality -, which offers a way of dissolving the pseudo-problem of epistemic immodesty, namely, the seemingly counterintuitive thesis that one can acquire rationally grounded knowledge that one is not in a radical skeptical scenario.
\end{abstract}

\section{Favoring and Discriminating Epistemic Grounds}

Disjunctivism about perceptual knowledge is not an orthodoxical view: contrary to modern philosophical tradition, one of its main tenets is that perception is sometimes factive and that non-factive states do not have the

Manuscrito - Rev. Int. Fil. Campinas, v. 39, n. 3, pp. 5- 28, jul.-set. 2016. 
same epistemic status as perception. Alternatively, a disjunctivist might say that there is no epistemic common-level between perception in paradigmatic cases and non-perceptive states, like dreams, hallucinations and illusions. The view is especially relevant against a variation of skeptical argument that hinges on the idea that our experience does not give us a rational basis for believing mundane proposition instead of skeptical hypotheses ${ }^{1}$. When dealing with skepticism, therefore, factivity is not enough: an interesting version of epistemological disjunctivism has to claim that perception is a factive rational basis for holding beliefs about the external world (at least in paradigmatic cases) $)^{2}$. Henceforth, I will assume the correctness of epistemological disjunctivism.

In order to advance the view without committing it with the seemingly absurd consequence that we have rational grounds to discriminate between actual possibilities - say, that there is a goldfinch yonder - and the relevant skeptical hypotheses - e.g., that I am an envatted brain hallucinating a goldfinch - Pritchard $(2012,2016)$ introduces an independently motivated distinction between favoring and discriminating epistemic grounds. Imagine I hold an apple and form the belief that it is a pacific rose apple $(p)$. An interlocutor could ask me how I know it. With this she could mean how I know that $p$ obtains instead of its being a red delicious apple $(q)$. This possibility is a close one, and it seems that I must be able to discriminate a pacific rose apple from a red delicious apple in order to know that $p$ perceptually. Things start to get interesting if we consider local skeptical possibilities. Imagine my interlocutor asks me how I know that it is a pacific rose apple instead of a perfectly manufactured counterfeit apple $(r)$. If this possibility is reasonably well-motivated ${ }^{3}-$ if we are both well aware that

\footnotetext{
${ }^{1}$ Brueckner (1994) is responsible for bringing this argument, which is now known as the underdetermination skeptical argument, to the contemporary epistemological debate.

2 I am using Pritchard's (2012) formulation, but other philosophers - such as Hinton (1967) and McDowell (1982, 2011) - express disjunctivist ideas differently. See Haddock and Macpherson (2008) for the differences between the varieties of disjunctivism.

3 'Reasonably' here means 'to be appropriately supported by reasons'. Moreover, as it will become clear in \$4, I am not using 'reasonably' and 'rationally' interchangeably.
}

Manuscrito - Rev. Int. Fil. Campinas, v. 39, n. 3, pp. 5- 28, jul.-set. 2016. 
counterfeit apples are abundant in this area, for instance - then my initial belief that $p$ was temerarious and does not amount to knowledge, for I would be unable to discriminate $p$ from $r$ just from looking. In order to know that $p$ obtains, then, maybe I would need to smell the putative apple, feel its texture more attentively, weight it and so on, which means I would need to appeal to accessible discriminating evidence. It is entirely another matter if $r$ is not reasonably well-motivated. If there is no particular reason to suppose that $r$ could be the case - if my interlocutor asks me out of the blue how do I know that $p$ because $r$ just could be the case - then there is no need to discriminate between $p$ and $r$ from obtaining. Favoring epistemic grounds (such as my current perception and my background knowledge) are enough to support the belief that $p$ over $r$ if $r$ lacks a reasonable motivation ${ }^{4}$.

The crux of the matter, argues Pritchard, is that radical skeptical possibilities, such as being a brain in vat, are necessarily reasonably unmotivated, for there is no particular reason that could be adduced in its support (Pritchard, 2016, p. 141). A skeptic would not (indeed, could not) claim that there is some evidence that supports the possibility that we are envatted brains, for this would be self-defeating. Neither there are accessible discriminating evidences one could discover to rule out radical skeptical possibilities like this one, for such possibilities supposedly undermine all of our putative knowledge at once - that is precisely what makes them radical. However, the epistemological disjunctivist is in a position to say that the propositions we come to believe everyday do enjoy favoring (nondiscriminating) epistemic support over radical skeptical possibilities, since our perception is a factive rational basis for believing. Now, the putative problem of epistemic immodesty arises if we join this view with the closure principle for rationally grounded knowledge - namely:

\footnotetext{
${ }^{4}$ This is analogous to the famous zebra case originally found in Dretske (1970): one sees a zebra in the zoo, but if there are available reasons to suppose that it might be a cleverly disguised mule, then one's epistemic position is surely undermined. In this case, one needs discriminative evidence to dismiss the possibility that it might be a cleverly disguised mule. However, if this possibility is not properly motivated, then one's epistemic position qualifies at least prima facie to knowledge.
}

Manuscrito - Rev. Int. Fil. Campinas, v. 39, n. 3, pp. 5-28, jul.-set. 2016. 
If $\mathrm{S}$ rationally knows that $p$ and $\mathrm{S}$ competently deduces $q$ from $p$, forming a belief in $q$ and retaining the rationally grounded knowledge that $p$, then $\mathrm{S}$ rationally knows that $q .{ }^{5}$

This principle enjoys some intuitive plausibility; it does not look like we could reject it with impunity. Moreover, epistemological disjunctivism per se offers no ground for the rejection of the principle, which is indeed an advantage of the view. If we combine epistemological disjunctivism with this closure principle, it follows that we can acquire rationally grounded knowledge of the denials of radical skeptical hypotheses. That we know in a rationally grounded way (even if not discriminatively) that we are not brains in vats, for instance, is what Pritchard takes to be a case of epistemic immodesty. He writes:

[...] If the epistemological disjunctivist extends her anti-skeptical line to this form of radical skepticism [closure-based radical skepticism] by contending that we can have rationally grounded knowledge of the denials of radical skeptical hypotheses, then it can look like an unduly strong response to the problem of radical skepticism $[\ldots]$ Epistemological disjunctivism, so construed, seems committed to embracing a kind of epistemic immodesty, in that intuitively we are unable to have rationally grounded knowledge of these propositions [denials of radical skeptical hypotheses]. (Pritchard, 2016, p. 179-180)

Epistemic immodesty consists in the possibility of acquiring rationally grounded knowledge - as opposed to mere externalist knowledge - of the denials of radical skeptical hypotheses, which seems to be a case of dogmatism. On a conception of rationality according to which to be epistemically rational implies to possess available reasons to believe (a conception we will challenge bellow), it is unintuitive to say that we have conclusive factive reasons to believe that radical skeptical hypotheses are

\footnotetext{
${ }^{5}$ Pritchard (2016, p. 13) calls this formulation diachronic because it differs from the classical formulation - namely: if one knows that $p$ and knows that $p$ entails $q$, one knows that $q$. Moreover, and importantly, the diachronic version of the principle avoids uninteresting counterexamples that affect the classical formulation. Without the restriction of rationally grounded knowledge, Williamson (2000, p. 117) originally expressed this principle diachronically under the name of intuitive closure.
}

Manuscrito - Rev. Int. Fil. Campinas, v. 39, n. 3, pp. 5- 28, jul.-set. 2016. 
false. This unappealing consequence would compel us to reject the disjunctivist thesis or the closure principle. Since this version of the closure principle is at least as plausible as epistemological disjunctivism, and that there is no independent ground to suppose both should be abandoned together, epistemic immodesty would motivate a reductio of disjunctivism itself. Alternatively, one might argue, the fact that epistemological disjunctivism entails epistemic immodesty turns out to weaken epistemological disjunctivism in comparison with other anti-skeptical positions, such as epistemological contextualism, which would concede to the skeptic that in certain contexts we do not know that radical skeptical hypotheses are false (thus being "epistemically modest").

We will inquire in $\int \S 4$ and 5 whether epistemic immodesty really is as problematic as it might seem. I resist the temptation to reject disjunctivism based on this consequence, for I contend that a more inclusive notion of epistemic rationality dissolves the apparent problem of epistemic immodesty. For now, we must take a closer look at moderate skeptical possibilities and see how they fit the schema of discriminating and favoring epistemic support (\$\$2 and 3).

\section{Dream Skepticism and Phenomenological Conjunctivism}

If radical skeptical possibilities are reasonably unmotivated by their very nature because they could not be supported by particular reasons, then a moderate skeptical possibility could, at least in principle, be reasonably motivated at the expense of having a narrower scope. The dream possibility fits the bill because it is possible to offer reasons in its favor, although it is traditionally taken to be less effective than the Evil Genius and similar hypotheses ${ }^{6}$. As a motivation, one could say most people often dream and, when they are dreaming, they falsely take those dreams to be veridical

\footnotetext{
${ }^{6}$ Since at least Descartes' Meditations, dream possibilities are taken to be ineffective against a priori knowledge. Even if this kind of knowledge does not exist, some general facts about our constitution - such as that we are sometimes awake and that most people dream, etc. - are presupposed by the dream argument and could not be threatened by it.
}

Manuscrito - Rev. Int. Fil. Campinas, v. 39, n. 3, pp. 5-28, jul.-set. 2016. 
representations of their surroundings. If we can reasonably motivate this moderate skeptical possibility, then mere favoring epistemic support in favor of $p$ is not enough to rule out the possibility of dreaming that $p$ (and, obviously, $p$ not being the case), for one must be able to discriminate between perceiving that $p$ and dreaming that $p$. This is a consequence of the thesis that a reasonably well-motivated alternative can only be discarded if a subject has discriminating epistemic support against it. Put in another way, the idea is that, for a large class of believed propositions about the external world, there is the nearby possibility of entertaining these propositions in a dreaming state, and this modal proximity is what makes the dream possibility so acute. One could argue, then, in the following fashion:

(I) If $\mathrm{S}$ has rationally grounded knowledge that $p$ then $\mathrm{S}$ is able to achieve rationally grounded discriminative knowledge that she is not dreaming.

(II) $\mathrm{S}$ is unable to achieve rationally grounded discriminative knowledge that she is not dreaming.

:. (III) $\mathrm{S}$ does not have rationally grounded knowledge that $p$.

(I) is based on the closure principle for rationally grounded knowledge, which seems to be beyond dispute. Therefore, if we want to reject the skeptical conclusion in (III), we must take a closer look at (II) and the motivation that lies behind it. The philosophical platitude that one is unable to achieve rationally grounded knowledge, in particular of a discriminative sort, that one is not dreaming is anchored in a phenomenological thesis call it phenomenological conjunctivism:

The content C of S's waking experience is phenomenologically indistinguishable, from S's point of view at any given time, from a content $\mathrm{D}$ of S's possible dreaming experience.

The justification for phenomenological conjunctivism is the fact that, when we are dreaming, we misleadingly take oneiric experiences as veridical representations of our surroundings, in a way that we are unable to distinguish between dreaming and perceiving. Therefore, in order to avoid the skeptical conclusion in (III), we need to undermine the phenomenological conjunctivist thesis, and this in turn depends on examining whether this fact supports phenomenological conjunctivism.

One way to do so is to dispute the fact itself (or the way this fact is usually construed). This can be done by claiming that we do not believe in the contents of our dreams, for dreaming that $p$ and believing that $p$ are

Manuscrito - Rev. Int. Fil. Campinas, v. 39, n. 3, pp. 5- 28, jul.-set. 2016. 
different mental events. Sosa (2007) explores this view based on the distinction between events that happen in dream and events that happen while one dreams ${ }^{7}$. Events in dream may encompass belief-like states, but that is different from the beliefs one has while awake and that survive in the background of one's conscience while dreaming. One could reinforce this distinction by arguing that believing is in principle open to rational evaluation, while dreaming is not. One should, after all, review one's beliefs given the accessible evidences, but it seems entirely out of place to rationally evaluate a belief-like state that happens in a dream.

One problem with this line of response is that it ignores what happens when one entertains a lucid dream, for lucid dreams do not seem to be completely devoid of doxastic states - indeed, it is reported that lucid dreamers are able to perform certain tasks, like counting time in the dream (LaBerge, 2000). Moreover, contrary to what Sosa claims, it is quite possible to believe in what happens in a dream during a waking experience: several times I seem to suddenly remember something during the day - say, that there were some fruits in the fridge - only to find out later that I had dreamt it. In this case, it seems that fragments of the dream played a doxastic role and could be rationally assessed in a waking experience. I can open the fridge in the morning and become genuinely surprised to find out there were no fruits there. Nightmares can serve as counterexamples as well: often when a dream takes a bad turn, one wakes up believing that so-and-so happened and it takes a while, and maybe a good deal of ambientation, to realize it had not. This suggests that a belief (or a belief-like state, if you will) formed in dream can transcend the dreaming state and become open to rational evaluation in a waking experience. If this is so, the idea of distinguishing beliefs from oneiric belief-like states does not seem appealing and the fact that we often take dreams to be veridical representations remains unscathed.

There is indeed an available alternative: to question whether the fact about our inability to distinguish in-dreams states from veridical states lends

\footnotetext{
7 Wittgenstein (1969) proposes a similar strategy: 'The argument "I may be dreaming" is senseless for this reason: if I am dreaming, this remark is being dreamed as well - and indeed it is also being dreaming that these words have any meaning' (\$383). See also $\$ 676$.
}

Manuscrito - Rev. Int. Fil. Campinas, v. 39, n. 3, pp. 5-28, jul.-set. 2016. 
the necessary support for phenomenological conjunctivism. Remember that phenomenological conjunctivism is a general thesis about the indistinguishability of a waking content $\mathrm{C}$, from S's point of view at any given time, from a content $\mathrm{D}$ of a possible dreaming experience. The fact that's under scrutiny, however, is that we cannot discriminate dream from reality in dream. I submit it is a non-sequitur to arrive at the general thesis from this fact, for it is plainly possible to discriminate waking experience from dreaming experience while awake. There is a grain of truth on asking for someone to pinch you to see whether you are dreaming (anecdotal as it may be), for waking experience is different from dreaming experience in a substantial way ${ }^{8}$. This point has been made in a slightly different tune by a few philosophers. Austin's enlightening thoughts on the matter deserve to be quoted at some length:

[...] We have the phrase 'a dream-like quality'. Some waking experiences are said to have this dream-like quality, and some artists and writers occasionally try to impart it, usually with scant success, to their works. But of course, if the fact [that 'delusive and veridical experiences' are not 'qualitatively different'] here alleged were a fact, the phrase would be perfectly meaningless, because applicable to everything. If dreams were not 'qualitatively' different from waking experience, then every waking experience would be like a dream; the dream-like quality would be, not difficult to capture, but impossible to avoid. (Austin, 1962, pp. 48-49).

Similarly, and more to the point, here is Rödl:

From the fact that, when I am fooled, I do not know that I am, it does not follow that, when I am not fooled, I do not know that I am not. When I know that $p$ as I perceive it to be the case, then I know

\footnotetext{
${ }^{8}$ Sosa intends to defend this conclusion by the distinction we mentioned above. Therefore, Sosa and I share the same conclusion, but I offer a different rationale. Here is his view on the matter: 'What enables us to distinguish the two contentidentical states is just the fact that in the dream state we do not affirm anythingnot that we are veridically perceiving an external world, nor that we are notwhereas in waking life we do knowingly perceive our surroundings. This by our lights suffices to make the two states distinguishable.' (Sosa, 2007, pp. 18-19).
}

Manuscrito - Rev. Int. Fil. Campinas, v. 39, n. 3, pp. 5- 28, jul.-set. 2016. 
that I perceive that $p$. Thus I am in a position to distinguish my situation from any possible situation in which I would be fooled, for, in any such situation, I would not perceive that $p$, while in the given situation I do. (Rödl, 2007, p. 158)

If we hold on to the idea that waking experience is fundamentally different from dreaming experience, then we are straightforwardly committed to the rejection of phenomenological conjunctivism: it is not the case that waking and dreaming experiences share the same phenomenology and are, therefore, indistinguishable. So it seems that, in order to deal with dream skepticism, we have to think of experience in terms of phenomenological disjunctivism. However, this result is dialectically insufficient to reject the premise on the skeptical argument that says it is humanly impossible to achieve rationally grounded discriminative knowledge that one is not dreaming, because we still need a reasonable explanation of how can we distinguish reality from dreaming. What exactly is present in a case and absent in the other?

\section{Actionism and Phenomenological Disjunctivism}

\subsection{Motivations and Relevance}

Recently Alva Noë proposed an independently motivated account of perceptual consciousness - what he called enactive approach (2004) and actionism (2012) - which offers a plausible rationale for phenomenological disjunctivism ${ }^{9}$. The basic tenet of this view is that conscious perception is an activity performed by the exercise of sensorimotor abilities. This means that the content of one's conscious perception is constituted by the practical way one can engage with the world.

Actionism is a phenomenological account that aims to do justice to our perceptual experience. Its main motivation is to explain two related facts

${ }^{9}$ For a classical work on the subject of embodied mind, see Varela, Thompson and Rosch (1991). As a critique of the philosophical consequences Noë draws from the experiments we mention bellow, see Prinz (2009). It is beyond the scope of this paper to present an extensive defense of this view.

Manuscrito - Rev. Int. Fil. Campinas, v. 39, n. 3, pp. 5-28, jul.-set. 2016. 
about our encounter with objects without appealing to representations as internal models of the world: first, the fact that perception is a perspectival event but is also about the objects themselves, in a sense regardless of the perceiver's point of view. For instance, as I look at a plate on the table, it seems to be oval or oblong from my current perspective, but I also perceive it as being round. In the second place, actionism explains the fact that objects present themselves as facets but also as wholes: as I look at the bookshelf in front of me, I see aspects of books, mostly their covers, but it is also plausible to say I am perceiving the books, not just slices of books. Both facts of our phenomenology are explained by the appeal to sensorimotor knowledge: I perceive the plate as round because I dispose of the practical knowledge to move and engage with the different aspects of it that unfold in my experience, and this practical knowledge allows me to grasp what stays constant when I perceive the plate, its roundness, and what shifts when I move around, its look or appearance. That I perceive objects in their entirety despite seeing only facets of them is explained by the virtual accessibility provided by my sensorimotor abilities to navigate in the environment: I perceive books and not only slices of their covers because I have the know-how to assume different perspectives and integrate them in a dynamic experience ${ }^{10}$.

Actionism is also in tune with empirical findings: cases of what Noë calls experiential blindness count as direct support in its favor (2004, pp. 8-11). Those cases are exemplified by experiments where a subject wears glasses with inverted lenses, which cause left and right (or up and down) to be switched in her visual field. The subjects in these experiments at first fail to integrate their perceptual stimuli and experience a period of confusion (Stratton 1897, Kohler 1951 and Taylor 1962). In a second stage, they slowly relearn how to operate with these stimuli and come to entertain episodes of conscious perception as if they were not wearing inverted lenses. Finally, when the lenses are removed, they undergo a period of confusion similar to

\footnotetext{
${ }^{10}$ Noë also aims to explain our perception of colors through actionism (Cf. Noë, 2004, chapter 4): although surfaces hardly are uniformly colored, we are perfectly able to distinguish the actual shade of a surface from the variations caused by the way light reflects on it on different angles.
}

Manuscrito - Rev. Int. Fil. Campinas, v. 39, n. 3, pp. 5-28, jul.-set. 2016. 
the one at the first stage and have to relearn once again how to operate with their perceptual stimuli. The best explication of what happens in these cases is that the subject is partially blind due to the 'inability to integrate sensory stimulation with patterns of movement and thought' (Noë 2004, p. 4), which is exactly what actionism predicts.

As for indirect support, competing views fail to explain cases of change blindness, where an individual does not consciously perceive changes that happen in her perceptual field (see Noë 2004, pp. 51-54, idem 2012, p. 93). This argument depends on the uncontentious premise that the environment we inhabit is heavily detailed. If our perception were pictorial, in the sense that it would capture all the details available in a single 'mental scene', then changes in the details of the environment would cause changes in perception. But this is not what happens. Experiments show we are prone to fail to perceive significant changes within our perceptual field if our attention is focused elsewhere (O'Reagan et al. 2000). Therefore, the phenomenon of change blindness shows that 'we don't make use of detailed internal models of the scene.' (Noë 2004, p. 52). In order to entertain states of conscious perception, then, we have to navigate through the environment, and this can only be done by the exercise of our sensorimotor abilities: from saccades to movements of the whole body.

According to Noë's actionism, perceptual consciousness is an embodied achievement - it necessarily involves an interaction with the environment, as the epistemological disjunctivist claims (see Noë 2012, pp. 63-67 for this same point) - and, more importantly, it requires the effective exercise of certain abilities that are not strictly intellectual, such as the ability to move one's own body in order to access what is available ${ }^{11}$. Here is Noë on the matter:

11 As Noë himself notices (2012, p. 69), the view bears some resemblance to conceptualism about perceptual experience, because experience is not given, instead it is mediated by one's understanding - in this case, practical understanding. Practical understanding or sensorimotor abilities would play a role analogous to the one played by concepts in the conceptualist view. Unless we are willing to stretch the very idea of conceptual capacities in order encompass sensorimotor abilities (which indeed was Noë's (2004) view on the matter), actionism does not amount to conceptualism. Note that an actionist approach to conceptual content seems to imply the rejection of Evans' Generality Constraint (Evans 1984, p. 75), according

Manuscrito - Rev. Int. Fil. Campinas, v. 39, n. 3, pp. 5-28, jul.-set. 2016. 
[...] Conscious reference is, in general, an achievement of the understanding. To see something - that is, for something to show up for one in conscious visual experience - or to refer in thought to something - that is, for it to show up in one's conscious thoughts is a matter of skillful access to the thing. [...] Conscious reference is a relation between a skillful person and a really existing thing. Where there is no really existing thing there can be no access or genuine availability; at most there can be the illusion of such. But the mere existence of the intentional object is not sufficient to guarantee that our thought or experience can involve it; for thought or experience to involve the object, the perceiver must be comprehending. (Noë, 2012, p. 27)

The view that our experience is constituted by our sensorimotor abilities to access the world is directly relevant to our present puzzle, because it offers a plausible explanation of the difference in kind between waking and dreaming experiences - thus justifying phenomenological disjunctivism. The idea here is that our dreaming experiences are not the result of a successful exercise of our sensorimotor abilities (nevertheless it is quite plausible that a different set of abilities is necessary for dreaming, which would explain the possibility of lucid dreaming and the fact that some people do not dream). This in turn explains why our experience is richer and significantly more consistent in actual perception: because we can navigate through our environment and access its details, while in dreaming there is no movement and practical understanding involved ${ }^{12}$. So (II) on the

to which an individual possessing conceptual capacities would be capable of generating an infinite number of thoughts. The reason for the rejection of the Generality Constraint is that, on the actionist view, the exercise of an individual's abilities are constrained by the environment she inhabits and could not be reproducible infinitely.

12 Noë, 2004, p. 214 draws a similar conclusion. He is not worried with dream skepticism in particular (indeed, he explicitly sets aside the question), but rather with answering the internalist objection that, if sensorimotor abilities were necessary for perception, how could we explain dream states? The common ground here is of course the fact that there is no sensorimotor abilities involved in dreaming experiences - and Noë's reply consists in explaining that waking and dreaming

Manuscrito - Rev. Int. Fil. Campinas, v. 39, n. 3, pp. 5- 28, jul.-set. 2016. 
skeptical argument above is false, and the argument from (I)-(III) is not solid. Moreover, if epistemological disjunctivism is a stronger anti-skeptical thesis when understood also in terms of a variation of phenomenological disjunctivism, in this case, the one supported by actionism; and if both actionism and disjunctivism consistently explain the differences between perceptual states and defective states - actionism through a phenomenological route and disjunctivism through an epistemological one then the explanation of these differences offered by the combination of the two accounts is more robust than the one offered by epistemological disjunctivism or by actionism separately

In the next two sections, I intend to show that if one is willing to accept actionism as the motivation for phenomenological disjunctivism in order to solve the skeptical puzzle based on the dream possibility, then epistemic immodesty - the apparently problematic consequence of epistemological disjunctivism and closure - is not really problematic at all, given a more inclusive notion of rationality suggested by an actionist view. But first we will take a closer look on what means to take actionism as an anti-skeptical thesis.

\subsection{Actionism as an Anti-Skeptical Thesis}

One could object that actionism is unable to properly motivate a response to the dream skeptical argument because it is an empirical thesis. This is a controversial claim, for actionism is intended to be an account of our perceptual experience - and, although it does enjoy empirical support (both direct and indirect), it is unclear whether describing our perceptual experience by appealing to our bodily skills is question-begging. After all, actionism seems to be an accurate account because we are embodied creatures, and supposing from the beginning that the only fitting kind of answer to the skeptic has to dispense our bodies and to depend exclusively on internal representations is to gratuitously shift the burden of the proof.

However, in order to answer this objection, we can concede that actionism is empirically motivated, but this does not undermine our overall

experiences are radically different precisely because sensorimotor skills are absent in dreaming states.

Manuscrito - Rev. Int. Fil. Campinas, v. 39, n. 3, pp. 5-28, jul.-set. 2016. 
strategy. As said in $\ 1$, we are assuming the correctness of epistemological disjunctivism and trying to avoid construing the consequence that we can have rationally grounded knowledge of the denials of radical skeptical hypotheses as a case of epistemic immodesty. The core disjunctivist idea is that perception yields a factive rational basis for believing and that nonperceptual states do not have the same epistemic status as perception. This allows us to block the skeptical argument according to which we are not entitled to rely on our perceptual states, because they would have the same epistemic status as deceptive states, and thus would not yield knowledge. So if epistemological disjunctivism is correct, we are entitled to take our perceptual states as sources of knowledge if we find ourselves in good epistemic circumstances. Among those perceptual states are the ones that support actionism, such as observations of our own experience and the relation it holds with our sensorimotor abilities and the empirical evidence in support of actionism.

There is a condition, however, that must be satisfied for epistemological disjunctivism to allow us to rely on an empirically based claim, viz.: that there are no reasonably well-motivated possibilities of mistake. If any such possibility is available, we do not find ourselves in good epistemic circumstances and should withhold our judgements concerning our perceptual states. Here one might take the skeptic's point as fundamental and argue that, given the dream possibility, we have to prove beforehand that we can acquire rationally grounded knowledge that we are not dreaming. This strategy could be properly said to be a refutation of the skeptical argument, and it does not seem like it can be done with anything less than a transcendental argument. I suggest a more cautious stance: there is no prior reason to suppose that the skeptic's point is more fundamental than common sense. Therefore, instead of refuting the skeptic, we aim to explain what is wrong with the skeptical argument by appealing to a commonsensical view according to which we have plenty of knowledge. On this strategy, skeptical arguments are taken to be pseudo-paradoxes, for they are constituted by prima facie plausible premises which entail unacceptable consequences. The strategy deployed here consists in explaining why a premise of the skeptical argument is merely apparently plausible, but is

Manuscrito - Rev. Int. Fil. Campinas, v. 39, n. 3, pp. 5- 28, jul.-set. 2016. 
actually misleading and should be rejected $^{13}$. This process is epistemologically relevant not only because it shows where exactly the skeptical argument goes astray, but also because it exposes features of our cognition that, if ignored, lead to unappealing consequences. Specifically in the case of the dream skeptical argument, we saw in $\int \$ 2$ and 3.1 that the premise (II), according to which one cannot acquire rationally grounded discriminative knowledge that one is not dreaming, is not only unjustified but also arguably false.

\section{Embodied Rationality}

Recall that epistemological disjunctivism is the thesis that perception is a rational factive basis for holding beliefs about the external world. If I know perceptually that $p$, and if the rational basis for my perceptual belief does transfer across the known entailment that I am not a brain in a vat, then I am able to acquire the rationally grounded knowledge that I am not a brain in a vat. This result is what Pritchard calls epistemic immodesty, and it does seem to be too strong of a consequence. This is so because usually when talking about rationality - hence about rationally grounded knowledge philosophers have in mind something as the possession of reasons that entail or non-deductively support the target belief. Ideally, those reasons can be articulated and brought about by a rational individual with the relevant conceptual skills when he or she is questioned. Call this the narrow conception of rationality, because it demands that the individual whose rationality we are assessing possesses a set of sophisticated cognitive skills. It follows that small children and non-human animals are a-rational for they do not fit this view normative framework.

It is something along these lines that Pritchard has in mind when he says that disjunctivism, as a philosophical position, enables us to have rationally grounded knowledge of mundane propositions (although he is not explicit about it). And this would be, indeed, one of the biggest gains of assuming a

${ }^{13}$ This is why the specific strategy I endorse is close to the one Pritchard calls 'undercutting' anti-skeptical strategy (Pritchard, 2012), for it aims not to respond to the skeptic, but to diagnose what is wrong with her argument.

Manuscrito - Rev. Int. Fil. Campinas, v. 39, n. 3, pp. 5-28, jul.-set. 2016. 
disjunctivist position: the fact that one perceives that $p$ is the rational source of one's belief that $p$, which entails $p$ in appropriate conditions. There is nothing mysterious in citing this fact as the rational source of belief formation: 'I know because I see it'. However, on this view of rationality, it certainly sounds odd to say that any perceived fact is a rational basis for denying a radical skeptical hypothesis, given that individuals in skeptical scenarios and in non-skeptical cases (like the real world) would seem to share the same phenomenological states. However, actionism enables us to reject this premise, for individuals in skeptical scenarios - as these are traditionally conceived - trivially do not enact their perceptual content. A brain in a vat has no body to exercise its sensorimotor abilities and thus lacks perceptual experiences altogether - as a radical disjunctivist would certainly predict. But what does this tell us about rationality? The view I am proposing here is that to perceive that $p$ is a rational basis of belief formation not because we can cite the fact that $p$ as the source and justification of the relevant belief, but because to perceive that $p$ is a form of achievement, particularly, an embodied achievement. It is with this account of rational cognition as achievement in mind that I suggest the following general definition of rationality, call it embodied rationality thesis:

$S$ is a rational agent iff $S$ is able to achieve a specific goal through the exercise of the relevant abilities in suitable conditions.

A perceptually conscious agent is rational, according to this view, because she achieves perceptual content (and forms beliefs correspondingly) by exercising her sensorimotor abilities in her interaction with the environment. Note that the ability to achieve a specific goal is dispositional and it implies some sort of stability, so it has to cover a large class of cases, for rational procedures are not compatible with lucky achievements. One can cash out this notion in modal terms: an agent is rational in achieving a specific goal if she achieves the same goal in most or all nearby possible worlds wherein she exercises the same abilities with the same end. Secondly, and relatedly, the notion of 'relevant ability' is intentionally vague, for the capacity to overcome shortcomings in which the specific abilities are not

Manuscrito - Rev. Int. Fil. Campinas, v. 39, n. 3, pp. 5- 28, jul.-set. 2016. 
available (or could not be properly exercised) is quite intuitively a distinctive aspect of rational individuals ${ }^{14}$.

The embodied rationality thesis is broader than the narrow notion mentioned above for two reasons. Firstly, it covers paradigmatic cases both of epistemic and of practical rationality. Note that if perception fundamentally depends on practical understanding, then the distinction between practical and epistemic rationality becomes somewhat blurred when it comes to perception as a source of rationally grounded knowledge ${ }^{15}$. Therefore, it is an advantage of the embodied view of rationality that it does not offer a clear cut between epistemic and practical rationality. Secondly, it is consistent with the idea, which is central to the narrow notion, that if a belief has some sort of appropriate propositional support, it is rationally held. For deductive and non-deductive justification certainly are cases of achievement of specific goals (deductively demonstrated belief or inductively justified belief ${ }^{16}$ ) through the exercise of the relevant abilities (inferential abilities, recognition of inferential patterns, sensitivity to reason and to new evidences) in suitable conditions (Gettier-style cases and skeptical scenarios aside). What the embodied rationality thesis explicitly rejects is the conditional that, if a belief is rationally held, then it enjoys some sort of appropriate propositional support. The reason for that is that now we can appreciate other forms of rationality in a more inclusive normative view, for non-human animals and small children are also able to successfully engage with their environment, in different levels and with different abilities (something that is corroborated by an evolutionary view) and form beliefs correspondingly ${ }^{17}$.

14 Variety and creativity in problem-solving strategies is fundamental for most conceptions of intelligence as well - see Cianciolo \& Sternberg (2004), mainly Sternberg's notion of successful intelligence (1995) -, plausible because intelligence and rationality are closely related.

15 Note that the appeal to an actionist theory of perceptual knowledge is not sufficient to entail that all knowledge-that is a kind of knowledge-how (or depends on practical understanding) - such as the view defended by Hetherington (2011).

${ }^{16}$ For simplicity, I am supposing here that abductive inferences are a subclass of inductive inferences.

17 Of course, that is not to say that humans and non-human animals share the same basic form of access to the world. On the contrary, the view we are advocating here

Manuscrito - Rev. Int. Fil. Campinas, v. 39, n. 3, pp. 5-28, jul.-set. 2016. 
Now, we distinguished two conditionals, both of which are central to the narrow notion of rationality. One is that if a belief has some sort of appropriate propositional support, it is rationally held - call this the inclusivist conditional and the other one is if a belief is rationally beld, then it enjoys some sort of appropriate propositional support - call this the exclusivist conditional. What could be the rationales behind both conditionals?

Certainly the idea behind the inclusivist conditional is that of truthconduciveness, for deductively valid inferences are truth preserving and inductively good inferences enhance the chances of its target belief being true. But note that being true is not the main aspect of the rationale for the inclusivist conditional, for a belief can be accidentally true and thus fail to qualify as rationally held belief. What is important here is the idea of achieving true beliefs through certain methods (specifically, in this case, deductive and non-deductive reasoning), and this is why the inclusivist conditional is contemplated by the embodied notion of rationality.

As for the exclusivist conditional, its rationale seems to rest in a confusion between, on the one hand, the act of making explicit the rational support a belief might have and, on the other, the rational status an agent might have independently of this act. This confusion arises in a similar manner when the topic is epistemic justification, as noticed by Alston (1988) - for focusing on our practices of giving reasons and responding to challenges inevitably leads us to the idea that only beliefs justify other beliefs. This is so because, if we partake in the dialogical game of giving and demanding justifications, we have to explicitly articulate them as propositions which we endorse. Similarly, we can focus on whether a propositional attitude is rational, given an available procedure to arrive at that attitude or we can focus on whether an individual is rational in having that attitude, given certain behavior that is explanatory of her attitude. The former forces a constraint of propositionality upon our view of rationality -

ensures that individuals possessing different abilities engage with the world differently, and thus instantiate different forms of rationality. How complex an individual's abilities are and how rich is her conceptual scheme are elements that transform the rationality she instantiates on her engagement with the world - this is why this view represents a transformative conception of rationality, as presented by Boyle (forthcoming).

Manuscrito - Rev. Int. Fil. Campinas, v. 39, n. 3, pp. 5- 28, jul.-set. 2016. 
hence the narrow notion - while the later allows us to say that an individual is rational by achieving certain goals through specific abilities. I find no independent reason to choose the first view, which entails the exclusivist conditional, instead of the second - unless one is supposing from the start that any broad notion of rationality is false.

\section{Epistemic Immodesty}

Recall that epistemic immodesty - the idea that one can acquire rationally grounded knowledge that one is not in a skeptical scenario - is a seemingly unappealing consequence of epistemological disjunctivism conjoined with the closure principle for rationally grounded knowledge. The distinction between favoring and discriminating epistemic grounds does not ease the discomfort, for even the possibility of acquiring non-discriminative rationally grounded knowledge that one is not in a skeptical scenario seems to be too strong. Pritchard's attempt to solve this puzzle is inspired by some of Wittgenstein's (1969) remarks on our epistemic practices, according to which all rational evaluations are local, viz., some propositions cannot be assessed in a rational inquiry. More to the point, according to Pritchard we cannot rationally evaluate the denials of skeptical hypotheses, because propositions, like 'I am not a brain in a vat', codify or express our binge commitments, which are 'visceral commitments on our part, commitments that must be in place in order to create the rational arena in which rational evaluations function' (Pritchard, 2016, p. 175). If this is the case, then hinge commitments cannot constitute (or be translated to, or be codified by) beliefs, for beliefs are essentially open to rational evaluation. A fortiori, they cannot qualify as knowledgeable propositions ${ }^{18}$. On this view, one cannot even form the belief (let alone the knowledge-apt belief) that one is not a brain in a vat on the ground that one perceives something to be the case, even if one's perception is factive and rationally grounded. The closure

18 Pritchard is careful to distinguish the view that hinge commitments cannot constitute (or be translated to, or be codified by) beliefs from the stronger thesis that hinge commitments are not propositional. One contender of the later view is Moyal-Sharrock (2004).

Manuscrito - Rev. Int. Fil. Campinas, v. 39, n. 3, pp. 5-28, jul.-set. 2016. 
principle for rationally grounded knowledge, then, would not apply to this sort of case.

Aside of creating an exception to the relevant closure principle, what may sound puzzling about Pritchard's strategy is that it seems entirely possible to believe that one is not a victim in a skeptical scenario. In order to accommodate this appearance, Pritchard has to deny that the phenomenology of our mental states is a privileged way of determining their nature. He writes:

This [hinge] commitment may feel like belief to the person concerned, in that its phenomenology may be identical to other, more mundane, beliefs that the subject holds. But the import of this point is moot once we remember that the phenomenology of a propositional attitude does not suffice to determine what propositional attitude is in play (Pritchard, 2016, p. 102).

Pritchard then offers the example of wishful thinking as a justification for the claim that the phenomenology of our mental states is not a reliable indicator of their nature. Note, however, that wishful thinking is not a standard case, unlike believing, which would explain why an individual who thinks wishfully has a propensity to fail to identify the nature of her mental state. Moreover, Pritchard is here advocating some sort of phenomenological conjunctivism, which would bring us back to dream skepticism (in particular, our solution to the dream skeptical argument, which consists in rejecting II, would not be available). The advantage of the embodied notion of rationality on this matter is that it offers a less onerous solution to the apparent problem of epistemic immodesty - and it is also Wittgensteinian in spirit (although I am not interested in presenting a faithful exegesis here).

The idea is that the attitudes concerning the propositions that codify our hinge commitments - such as 'here is a hand' - do not come for free. They are not the goal of a rational evaluation, in the sense that they could not enjoy rational support narrowly conceived (at least in most normal circumstances). But they are achieved by the way we engage with the world, which is explained by our sensorimotor abilities. Our attitudes concerning these propositions then, on the light of the embodied rationality thesis, are rational. The same applies to the denials of radical skeptical hypotheses: we

Manuscrito - Rev. Int. Fil. Campinas, v. 39, n. 3, pp. 5- 28, jul.-set. 2016. 
form the beliefs in the denials of radical skeptical possibilities based on the successful exercise of our sensorimotor abilities: it is because we are successfully interacting with the world that we believe we are not brains in vats for instance. Since beliefs like these are achieved through the exercise of our relevant abilities in suitable conditions, we are rational in believing that we are not victims in skeptical scenarios. Furthermore, given epistemological disjunctivism, our perception in good circumstances is factive - it follows that the beliefs in the denials of radical skeptical hypotheses constitute rationally grounded knowledge. ${ }^{19}$

This point is on a par with some of Wittgenstein's (1969) passages that show a struggle with the finding that rational evaluations are dependent upon something that is not open to rational evaluation itself, namely our most fundamental practices:

Giving grounds, however, justifying the evidence, comes to an end;but the end is not certain propositions' striking us immediately as true, i.e. it is not a kind of seeing on our part; it is our acting, which lies at the bottom of the language-game. ( $\$ 204$, my emphasis)

[...] As if giving grounds did not come to an end sometime. But the end is not an ungrounded presupposition: it is an ungrounded way of acting. ( $\$ 110$, my emphasis). ${ }^{20}$

That our epistemic practices of 'giving grounds' are based on 'an ungrounded way of acting' is a way of expressing the locality of our rational evaluations, for we cannot adduce reasons in support of our most fundamental presuppositions, our hinge commitments. But it does not follow from this fact that 'our acting' is irrational, not as long as one conceives of rationality as something embodied. Epistemic immodesty, then, is not a problem on this view because we cannot but act the way we do, viz., by engaging with the world through the cognitive apparatus we are endowed with. This consequence is best understood not as a matter of

19 Note that the claim I am advancing here is bolder than the idea that we are pragmatically justified in accepting that we are not victims in skeptical scenarios. For this view, see Wright (2004).

${ }^{20}$ See also $\int \$ 148,232$ and 342.

Manuscrito - Rev. Int. Fil. Campinas, v. 39, n. 3, pp. 5-28, jul.-set. 2016. 
immodesty, but as a depiction of our constitution as cognitive agents. This is also obliquely contemplated by Wittgenstein for, although it is a contingent matter which hinge commitments we hold fast to in order for our rational evaluations to be possible, that some need to stay put is not contingent ${ }^{21}$ :

But it isn't that the situation is like this: We just can't investigate everything, and for that reason we are forced to rest with the assumption. If I want the door to turn, the hinges must stay put $(\$ 343)^{22}$.

\section{Concluding Remarks}

The suggestion that rationality is not something purely intellectual and unconstrained by our worldly actions arises naturally from the sort of actionist account of perception I proposed as a solution to the dream argument. This view then allows us to say that epistemic immodesty is not a problematic consequence of epistemological disjunctivism and closure for rationally grounded knowledge, because it is not problematic at all. But it also has a consequence that seems to be counterintuitive or straightforwardly unacceptable: individuals in skeptical scenarios do not engage with the world - by the most intuitive way to construe such scenarios - and could not, therefore, be said to be rational if we accept the embodied view of rationality. They achieve nothing, they fail systematically. Nonetheless, it seems that we can imagine the victims in skeptical scenarios as being epistemically responsible and avoiding inferential pitfalls - which is something cardinal to any intuitive notion of rationality. How can the view defended here deal with this objection? This is a problem to be addressed in the future.

${ }^{21}$ Wittgenstein addresses the fact that there is not sharp and definitive distinction between our hinge commitments and the rest of our rational evaluations with the riverbed metaphor ( $\$ \$ 96-99)$.

${ }^{22}$ See also $\$ \$ 152$ and 235.

Manuscrito - Rev. Int. Fil. Campinas, v. 39, n. 3, pp. 5- 28, jul.-set. 2016. 


\section{Bibliography}

ALSTON, W. “An Internalist Externalism.” Synthese 74, PP. 265-83, 1988.

Austin, J. L. Sense and Sensibilia. London: Oxford University Press, 1962.

BOYLE, M. "Additive Theories of Rationality: A Critique." European Journal of Philosophy. http://nrs.harvard.edu/urn-3:HUL.InstRepos:8641840. Forthcoming.

Brueckner, A. "The Structure of the Skeptical Argument." Philosophy and Phenomenological Research 54 (4), pp. 143-59, 1994.

Cianciolo, A, T., Sternberg, R. J. Intelligence - a Brief History. Malden: Blackwell Publishing, 2004.

Dretske, F. "Epistemic Operators." The Journal of Philosophy 67 (24), pp. 1007-23, 1970.

Evans, G. The Varieties of Reference. Edited by John McDowell. Oxford: Clarendon Press, 1982.

Haddock, A. MacPherson, F. "Disjunctivism: Perception, Action, Knowledge." Oxford: Oxford University Press, 2008.

Hetherington, S. How to Know - a Practicalist Conception of Knowledge. Malden: Wiley-Blackwell, 2011.

Hinton, J. M. "Visual Experiences.” Mind 76 (302), pp. 217-27, 1967.

PRINZ, J. "Is Consciousness Embodied." In The Cambridge Handbook of Situated Cognition, edited by Philip Robbins and Murat Aydede, 41936. Cambridge: Cambridge University Press, 2009.

KOHLER, I. "Formation and Transformation of the Perceptual World." Psychological Issues 3 (4), pp. 1-173, 1951.

LABERGE, S. "Lucid Dreaming: Evidence and Methodology." Behavioral and Brain Sciences 23 (6), pp. 962-63, 2000.

MCDowell, J. "Criteria, Defeasibility, and Knowledge." Proceedings of the British Academy, no. 68, pp. 455-79, 1982

- Perception as a Capacity for Knowledge. Milwaukee: Marquette University Press, 2011.

MOYAL-SHARrocK, D. Understanding Wittgenstein's On Certainty. Hampshire: Palgrave Macmillan, 2004.

NOË, A. Action in Perception. Cambridge, Massachusetts: MIT Press, 2004.

- Varieties of Perception. Cambridge, Massachusetts: Harvard University Press, 2012.

Manuscrito - Rev. Int. Fil. Campinas, v. 39, n. 3, pp. 5- 28, jul.-set. 2016. 
O’Reagan, J.K, Deubel, H., Clark, J.J., Rensink, J.A. "Picture Changes during Blinks: Looking without Seeing and Seeing without Looking." Visual Cognition 7 (1.2.3), pp. 191-212, 2000.

RobBins, P., Aydede M. The Cambridge Handbook of Situated Cognition. Cambridge: Cambridge University Press, 2009.

PritChARD, D. Epistemological Disjunctivism. Oxford: Oxford University Press, 2012.

- Epistemic Angs: Radical Skepticism and the Groundlessness of Our Believing. Princeton: Princeton University Press, 2016.

RöDL, S. Self-Consciousness. Cambridge, Massachusetts: Harvard University Press, 2007.

SosA, E. A Virtue Epistemology, Vol I. New York: Oxford University Press, 2007.

STENBERG, R. J. "The Theory of Successful Intelligence." Interamerican Journal of Psychology 39 (2), pp. 189-202, 2005.

STRATTON, G. M. "Vision without Inversion of the Retinal Image." Psychological Review 4: 341-60, pp. 463-81, 1897.

TAYlor, J. G. The Behavioral Basis of Perception. New Haven: Yale University Press, 1962.

VARElA, F.J., THOMPSON, E., ROSCH, E. The Embodied Mind. Cambridge, Massachusetts: MIT Press, 1991.

Williamson, T. Knowledge and Its Limits. Oxford: Oxford University Press, 2000.

Wittgenstein, L. On Certainty. Edited by Denis Paul and G.E.M. Anscombe. Oxford: Basil Blackwell, 1969.

Wright, C. "Warrant for Nothing (and Foundations for Free)?" Proceedings of the Aristotelian Society 78, pp. 167-212, 2004.

Manuscrito - Rev. Int. Fil. Campinas, v. 39, n. 3, pp. 5- 28, jul.-set. 2016. 